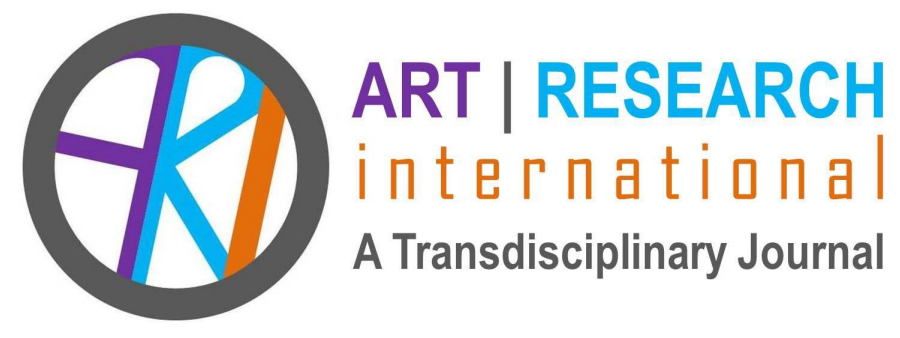

\title{
TUMBLING FROM EMBODIMENT TO ENFLESHMENT: ART AS INTERVENTION IN COLLECTIVE AUTOETHNOGRAPHY
}

\author{
Kelly W. Guyotte \\ University of Alabama \\ kwguyotte@ua.edu \\ Brooke A. Hofsess \\ Appalachian State University \\ hofsessba@appstate.edu \\ Gloria J. Wilson \\ Virginia Commonwealth University \\ gwilson25@vcu.edu \\ Sara Scott Shields \\ Florida State University \\ skshields@fsu.edu
}

Kelly W. Guyotte is an Assistant Professor of Qualitative Research at the University of Alabama. Her interests focus on qualitative methodology, pedagogy, and arts-based research.

Brooke A. Hofsess is an Assistant Professor of Art Education at Appalachian State University immersed in aesthetic and poetic approaches to inquiry contemplating teacher education and renewal. 
Gloria J. Wilson, a Visiting Assistant Professor of Art Education at Virginia Commonwealth University, engages in critical arts-based inquiry and approaches to affect social transformation.

Sara Scott Shields is an Assistant Professor of Art Education at the Florida State University. Her research interests include arts-based approaches to research and learning.

Abstract: We, the four authors, found ourselves swept into the tenure process, tumbling as we inquired into what this transition meant to each of us and to all of us. Through a methodological grounding in collective autoethnography - and expanded by art intervention, we came together in our inquiry to explore key experiences as new professors, asking how we individually, collectively, and aesthetically move(d) through our transitions into tenure track assistant professorship. We found it was through the embodied acts of listening, attuning, and responding with/in our flesh as women and as researchers that we felt the friction of Tenure as another body in our collective. Tenure provoked our poems, tears, arguments, victories, aches, paintings, tenderness, stitches through fabric, movements, and identities. This article serves as a methodological unpacking of our arts-based research process that used Tumblr, individual and collective artmaking, and visits to each other's homes. While our collective work seeks new potentialities of understanding our tumbling selves as women, artists, and researchers new to the academy, we also see this work as opening our stories to the world in order to create new possibilities beyond our project.

Keywords: arts-based research; autoethnography; methodology; collaborative research; art intervention; embodiment 


\section{Tenure: Will you stop your tenure clock after the baby arrives? I saw your journal pages...}

Brooke:

we stand side-by-side / at a wall of sinks / her eyes trace the profile of my belly / she asks, anything special happen over the summer? / heat and color flood my neck and pool in the hollows of my cheekbones / my facade puddling into vulnerability on the bathroom floor / I wasn't ready to tell anyone

reading / searching / planning / sometimes in the middle of the night / when I know I should be sleeping / pedagogy can grab hold of you / in those weary hours

it is near dusk / the building has settled into quietude / my mailbox holds two academic journals / my writing lives inside both / without realizing it / I take them with me / to the threshold of our new chair's office / do you have a minute? / he shakes my hand / when I tell him I'm applying for maternity leave / this spring

the walk between my office and the art education classroom / traces the curves of our mountain town / my breath quickens and shallows / it occurs to me / I can't scurry between them like I used to / I can't push myself like I used to

my laptop screen glowers at me / judging my lack of progress / my forehead aches / my stomach unsettled / papery moths tap tap buzz / on the window / where the forest line slowly dissipates / becoming a swathe of blue-then-black / the focus and intensity I have cultivated in my writing practice weakens / as my attention shifts and pulls / to the dramatics happening inside my body

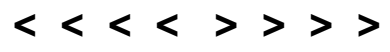

\section{Introduction}

It is often through moments of change, through meaningful shifts to our seemingly known world, that we are invoked to (re)consider the spaces we inhabit, our movements, and the ways in which our bodies respond in such spaces. Over the past four years, we, the four women authors, have all found ourselves awakened to these considerations as we graduated from the same art education doctoral program and transitioned into different tenure-track positions in the southeastern United States. Our 
respective pasts enfolded with present shifts as we each reached toward uncertain futures, and we found ourselves swept into the tenure process, tumbling, stumbling, stuttering as we inquired into what this transition meant to each of us and to all of us.

Through a grounding in collective autoethnography - and expanded by art intervention, we came together in this inquiry to both stay connected and to explore key experiences in our academic movements as new professors. As a movement, art intervention "applies to art designed specifically to interact with an existing structure or situation, be it another artwork, the audience, an institution or in the public domain" (Art Intervention, para. 1). We take up the notion of art intervention through a conceptual perspective that originated with artists endeavoring to transform their role in society, and "thereby society itself" (Art Intervention, para. 1). Often art interventions spark social movements and, ultimately, change. Our goal with art intervention as a form of artbased inquiry, then, is to make visible and transform the conversations about women on the tenure track by exploring how art can intervene within the academy. In this inquiry, the process of artmaking cultivated myriad spaces for us to reflect upon on our embodied experiences as we traversed the tenure track. To this end, our work seeks new potentialities of understanding ourselves as artists and researchers in the academy, while also opening our stories to the world in order to create new possibilities beyond our project.

While the primary focus of our project was an interest in the experience of women moving towards tenure, the methodological implications became equally important; moving us to ask the question: How does art intervene in collective autoethnographic research, allowing four women to speak to the experience of becoming tenured? Thus, we turned to both arts-based inquiry and collective autoethnography as our methodological lenses. Our data, based on embodied experiences, became enfleshed through various and lively forms, including Tumblr postings, art making (paintings, visual journal pages, drawings, fiber arts, handmade books, mixed media, videos, installation, and even relational, conceptual art pieces), and journeys to one another's homes. What became significant through our movements between embodiment (the affective, what we felt through our bodies) and enfleshment (how those feelings were clothed in artful form), was how we began to articulate our experiences with Tenure 1 as an omnipresent body in our academic experiences. Through our continued engagement with these data, we became awakened to Tenure speaking with and against, questioning and provoking, motivating and inspiring us as we tumbled on the tenure-track. Tenure became a body in our collective work, not corporeal, yet one with real material effects (and affects). 
In our experiences as women on the tenure track, and through our realization of the presence of Tenure, it was our awareness of movements between embodiment and enfleshment that collectively jolted us. The importance of embodiment is expressed by Madeleine Grumet who cautioned that women in the academy "have kept silent for so long now that we have forgotten that knowledge from and about the body is also knowledge about the world" (1988, p. 3). In what follows, heeding her wisdom, we attend to the jolts as well as our knotted stomachs, restricted breathing, laughter, relief, uncontainable

“In our experiences as women on the tenure track, and through our realization of the presence of Tenure,

it was our awareness of movements between embodiment and enfleshment that collectively jolted us." tears, blood becoming heated. Our bodies - full of warnings, triumphs, exhaustions, and sorrows, have led us to pick up a needle and thread, paint alongside our children, cut and tear paper, draw with mother's milk, capture still and moving images with our cameras. What is felt in our bodies becomes enfleshed through our art.

This article centers on two artful movements between embodiment and enfleshment. To begin, we demonstrate how Tenure's presence, felt in our bodies as women pursuing tenure, became enfleshed in our Tumblr posts. Alongside this, we explore our methodological turn to arts-based research as a means of intervening in collective autoethnography, with artmaking serving as the process through which our embodied experiences became enfleshed. We open this work by situating our study in relation to other literature related to women on the tenure track and ground our methodological lenses. Next, we unpack our theoretical framework, grounded in the work of Grumet, acknowledging the embodied acts of listening, attuning, and responding with/in our flesh that we recognized Tenure as a body among our collective. We then move toward an enfleshment of both Tenure and Tumblr, discussing how Tumblr expanded beyond its virtual space and inspired our material arts-based research practices and how Tenure affected each of our bodies. Our paper concludes with implications for this work in relation to art and research. Finally, interwoven and intervening throughout this article, we include Tumblr postings by each of the authors that have been crafted into conversations with Tenure. These interventions, extending from our concept of art intervention make visible our bodily responses, and serve as a playful nod to O'Donoghue's (2015) assertion of arts-based research as intervening in and constructing the world. 
This project enfleshes what our bodies have felt, and often what they still feel, as we tumble on the tenure track.

\section{Exploring Women on the Tenure Track}

Though we share our identification as women, we find ourselves embodying differences that must be considered in our encounters (and interventions) with/in academic cultures. We are: in our 30s and 40s; with Brown skin and White skin; at teaching-oriented and research-intensive institutions; with and without spouses; with and without children; experiencing different expectations for academic performance. These differences are important to note, as they are made visible in the narratives that intervene throughout this article. Further, such differences point to the polyphony of women's identities and experiences in the academy - positioning "woman" not as a homogeneous descriptor, rather envisioning woman as plural, complex, and intersectional. As women, and with an interest in how women navigate the tenure track, we now turn to the literature on women in the academy to contextualize what has been done, and how our work dialogues with the work of others.

Literature on women in academia, particularly women on the tenure track, is abundant. With the number of women in faculty positions in 2013 comprising $49 \%$ of institutional appointments and the number of women attaining full professorship at only 9\% (Flaherty, 2016), there are many lingering questions about how women experience the tenure track. Along these lines, existing studies have explored issues such as the gender gap in higher education, noting the declining percentages of women among faculty as they move up the tenure and promotion ladder (Drakitch \& Stewart, 2007) as well as the significantly lower number of women faculty members at research intensive universities (Marschke, Laursen, Nielsen, \& Ranking, 2007). Further, the issue of differing expectations between men and women in academia has also been the source of much interest (e.g. Bleijenberg, van Engen, \& Vinkenburg, 2013; Gasser \& Shaffer, 2014), particularly when there is evidence that women experience disproportionately higher service loads (Guarino \& Borden, 2017). These differences in the academic experience have been explored by way of the gendered expectations that women (Bleijenberg et al., 2013) and women of color (Bhattacharya, 2016) as "others" come to bear.

Much of the literature on women in academia, however, focuses on a prevalent source of tension among women academics, a tension felt by each of us at different times and in different ways - that of motherhood. Extending from O'Reilly's (2009, 2008, 2006) extensive work on mothering, questions of motherhood in academia often taken 
up whether or not to have children (e.g. Gasser \& Shaffer, 2014), when to have children (e.g. Armenti 2004a, 2004b), and how women with children experience academia (e.g. Guyotte, 2018; Hirakata \& Daniluk, 2009; Hofsess, 2018). While many of these discussions pointed to the challenges of balancing work life and home life, some women academics have reported the beneficial reciprocity between the two (Penney et al., 2015). Notable amongst these dialogues is the presence of the tenure clock and its production and effects on the experiences of women, most often centered on childbearing and child-rearing. These persistent references to the tenure clock are reflective of our own realizations about the place of Tenure in our academic experiences, which are made visible in the art interventions woven throughout.

Taking on this project as an autoethnographic art intervention - one that speaks to and with the culture/structure of tenure track academia - nudged us to consider how others have artfully intervened in such spaces. As a methodological frame for this work, arts-based research speaks to our sensibilities as artists and art-artist educators. We value the potential offered by visual languages to speak to affective qualities of experience (Barone \& Eisner, 2012; Eisner, 2002), and we align our thinking with artsbased researchers who discuss this approach as a means of creating and intervening in the world (O'Donoghue, 2015). Other women arts-based researchers have used academia and the tenure track as inspiration for their own inquiries, visually mapping their journeys in "Tenureland" (Savage, 2015) or collaboratively exploring the coexistence of motherhood and academia through narratives and visual materializations of "mothering curricula" (Poling, Guyas, \& Keys, 2012). We situate our work alongside these inquiries to add to the dialogues, both visual and verbal, as we further consider Tenure in our movement from embodiment to enfleshment, as well as what this means for arts-based collective autoethnographic research.

\section{Arts-Based Research and Collective Autoethnography}

As we set out in this inquiry trying to find a way to navigate what Savage (2015) termed "Tenureland," we intuitively knew that writing was not enough to effectively capture the nuances of our experience as women on the tenure track. Endeavoring to stay true to our identities as artists and artist-educators, we also embraced artmaking as an essential part of our work. Even as we collaboratively and artfully documented our experiences in the space of Tumblr, our digital work always seeped into our non-digital artmaking, and vice versa. This seepage led us to realize that we needed both collective autoethnography and arts-based research as grounding methodologies, which we discuss in the sections that follow. Following this, we move through the different modes of being together we engaged in during this inquiry. These include a shared Tumblr site, relational artmaking, an exhibition, and a shared visual journal. The goal of this 
discussion is to inquire into a central question for this paper: How might artful ways of processing be uniquely positioned to allow four women to speak to the experience of becoming tenured?

\section{Arts-based Research}

Susan Finley explained, "arts-based inquiry is uniquely positioned as a methodology for radical, ethical, and revolutionary research that is futuristic, socially responsible, and useful in addressing social inequities" (2008, p. 72). As such, we begin with a discussion of our first methodological influence, arts-based research. Drawing on Finley's (2008) model of arts-based research (ABR), we see our work existing with the hyphen, or the spaces between, the work of an artist and that of a researcher. The hyphen "creates a place where epistemological standpoints of artists and social science workers collide, coalesce, and restructure to originate something new and unique among research practices" (p. 73). Unique to this mode of thinking about ABR is the focus on the arts' ability to not just speak to, but also against social inequities. As a methodology, ABR challenges traditional notions of knowing and disrupts the hierarchy of the academy. Embracing this disruption, we created artwork that explored our lived experiences on the fringe of a field often run by White men in positions of power. The arts cultivated both space and time to attend to our nuanced, affective experiences as some combination of woman, Black, White, single, married, mother, tenure track, assistant professor, and artist.

While much of our work was created in the safe spaces provided by our collaboration, this work was also exhibited in galleries at some of our institutions. By putting our deeply personal view of the academic world on display, we hoped to disrupt the structure of the academy and draw attention to the inequities we found ourselves facing as we navigated the tenure process, both empowered and oppressed by the potentialities of our gendered and racialized bodies. Finley's (2008) call for ABR that is public, passionate, problematizing, and participatory is a weighty one. And while this project has addressed these calls for action with different intensities, it has begun to problematize both our shared and individual experiences on the tenure track. By drawing upon multiple modes of creation, including painting, drawing, sculpture, sewing, and installation we hope to do as Finley suggests and use this artistic collaboration to provide multiple entry points into the work. In addition, we draw inspiration from Leavy (2015) who discusses the important role that technology has in arts-based practices, thus embracing Tumblr as yet another mode of creation. The potentiality of these multiple entry points pushed us to consider what the world of ethnography might have to teach us, individually and collectively, about what it means to be arts-based researchers. 


\section{Collective Autoethnography}

As methodology, autoethnographies are situated at the intersection of art and science and involve systematic analyses of the self as situated within culture(s) combining qualities of autobiography and ethnography (Ellis, Adams, \& Bochner, 2011). Collaborative, or collective, autoethnographies, however, bring together multiple researchers through co-constructed yet often ambiguous, uncertain, and sometimes contradictory perspectives of cultural experiences (Ellis et al., 2011). For us, this conceptualization points to collaborative autoethnography and arts-based research as working toward common goals - art providing a space to deal with the ambiguity, uncertainty, and contradiction that comes from bringing together multiple perspectives. Further, Langer explained, "scholars in ethnography have much to contribute to those initially educated as artists, and artists well versed in the creative process and products . . . have much to offer ethnographers" (1951, p. 29). Therefore, we do not see these methodologies as distinct in our collective inquiry, but as congruent and mutually informing.

While others have used the term collective in autoethnographic work (e.g. Cord \& Clements, 2010; Kidd \& Finlayson, 2010; Pithouse-Morgan, Naicker, \& Pillay, 2017; Santiago, Karimi, \& Arvelo Alicea, 2017), we employ it as a playful nod to the notion of artist collectives that bring together practicing artists who work toward a shared goal, yet move fluidly between independent and collective artistic action. Embracing a postmodern sensibility, our collective research approach attends to each individual's experience in the culture(s) of higher education, while also exploring how these experiences comprise a complexly collective and dialogic process of autoethnographic meaning making (Chang, Ngunjiri, \& Hernandez, 2013). Thus, we share ownership of this research while concurrently striving to preserve the uniqueness of our individual experiences. In what follows, we turn to the space of our initial inquiry, Tumblr, and begin describing our methodological process.

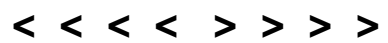

Sara: With dirt from the graveyard still caked in my shoes I came to work today. No time to feel grief, no time to unpack, no time to stop. l've been running too fast. Pushing forward with an agenda, a mission, a plan. When I got home I cried in the bathroom - shamefully, with the door closed.

Tenure: He knew you were in there, distressed and sobbing... I saw him standing by the door, wanting to knock. 
Sara: I feel like I can't breathe sometimes. I give love to the things that matter the most (my work, my husband, my students) and then feel empty and drained at the end of the day. I can't help but wonder is there room for anything else? I don't have the words for these feelings. It is like all at once I have tuned into the pulsing coming from my womb -a true awareness of one of the things that makes me a woman...I hate it. There is this real struggle happening between my head and my heart...I hope there are others that feel this way.

Tenure: You don't have to make a decision now; you have too much to do.

Sara: And still I run - feeling a need to both stop and go in the same minute, knowing this pace is unsustainable, I think back to my childhood in the Quaker church. A central tenet of this faith is a belief in everyone's inner light. I grew up believing that we all have a light, and our goal as spiritual beings is to nurture that light until it is so bright that others can't help but see it. Sometimes I worry for my light.

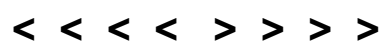

\section{Posting Tumbling Selves}

Tumblr ${ }^{2}$ is a free blog site that invites users with the ability to follow, post, and share through multiple expressive formats. Text, photographs, audio, video, quotes, web links, and chats comprise the seven button options that appear on each user's dashboard, as well as the opportunity to post either to the online Tumblr community or privately to one's own page or a private group. As artists, we were enamored with the multimedia possibilities that Tumblr provided and used the site as we began our artsbased collective autoethnographic journey in fall 2014 when Kelly, Gloria, and Sara prepared to begin tenure track positions, and Brooke looked toward her second year on the tenure track. Tumblr was selected because we could keep our posts private between our collective, it afforded us the opportunity to work through multiple expressive modalities, and it served as a virtual record of our temporal movements. To be sure, our posts reflected this flexibility and included artwork, photographs, videos, poems, sketches, conversation snippets, and experimental and narrative writing. As visible in Figure 1, our posts worked across modalities to explore the fluidity of our identities as academics, partners, mothers, women, and "Blackademic." Figure 1 illustrates some of the broader themes that weaved in and out of our Tumblr postings, and that inspired the individual artmaking we discuss below. 


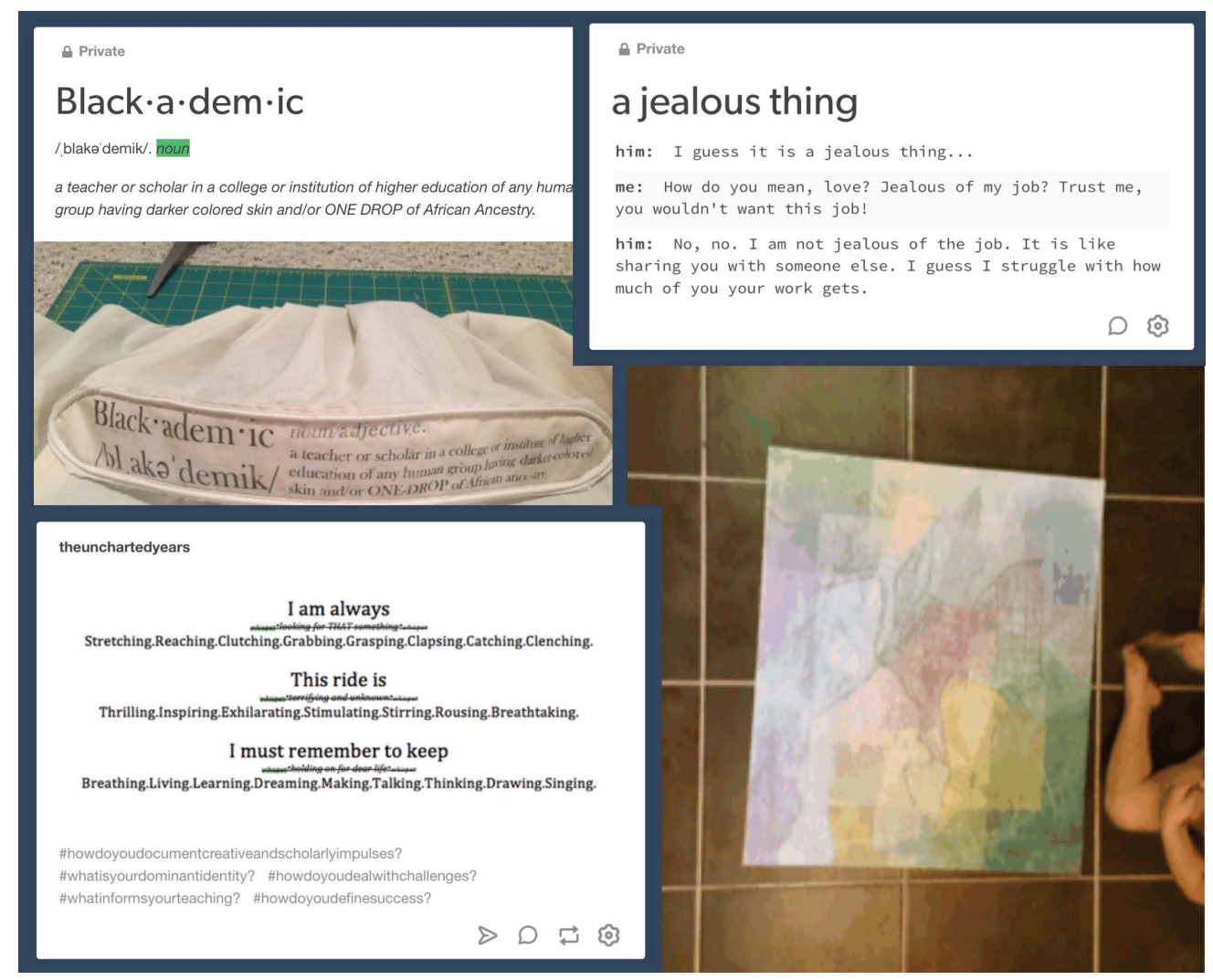

Figure 1. Snapshots of Tumblr postings

As we began our "data" generation, our living-inquiry, we each committed to writing (at least) three Tumblr posts every month during the first eighteen months of our study. Initially, we opted to focus one post each on the tenure track foci of teaching, research, and service, with an inherent interest in how we were moving through these facets of academia. However, as time passed our postings became more emergent, fluid, and more immediate to the thoughts and experiences that infiltrated our daily lives. We began to write spontaneously about those things that provoked, inspired, and moved us. Thus, the initial structure was productively disrupted as our lives shifted.

Even as we moved beyond teaching, research, and service as topics of our postings, the notion of tenure shadowed us. Nearing completion of our first twelve months of postings, we travelled to Sara's home and gathered around her kitchen table with the private Tumblr page flickering on our respective laptops. As we read through our postings, sometimes aloud, we developed a form of hashtag ${ }^{3}$ analysis that allowed us to map connections between each of our postings and across authors. Hashtags are often used on social media sites as keywords to topically organize online content and to connect to other postings/users (Bledsoe, Harmeyer, \& Wu, 2014). Other researchers have used hashtags as data themselves through analyzing their use in online 
environments and discourse (e.g. Araujo, Neijins, \& Vliegenthart, 2015; Bledsoe et al., 2014; Drüeke \& Zobl, 2016) and even counting and tracking their frequency of use (e.g. Hindman, Bukowitz, Reed, \& Mattingly, 2017; Sanderson, Barnes, Williamson, \& Kian, 2016). We, however, created the hashtags and used these designations to help map connections between our Tumblr postings with a more qualitative intent - to help us understand the content of our postings as well as how the hashtags related, connected. Thus, we framed the hashtags as questions, rather than as statements, for each of our Tumblr postings as a means of mapping how they connected, ruptured, jumped, and jolted (e.g. \#Howdoyoumakedecisionsaboutfamily, \#Howdotenurestoriesimpactyou).

During our reading and hashtagging, we felt the presence of Tenure in our postings especially as we noticed the collapse of scholarship/life/teaching/creating/ serving into an entanglement that became impossible to tease apart. It was through a continued and multilayered analysis that Tenure emerged as a body that had material effects on our tenure track movements. The hashtag questions we posed as a means of connecting/organizing/mapping our postings began to morph into an omniscient voice that transcended our individual experiences and geographic locations, and we found we could no longer dismiss Tenure's presence even as it ebbed and flowed in our postings. As seen in our interventions, we made Tenure visible as a force of vitality in our autoethnography - a body who inquired, nudged, challenged, and, at times, caused us to tumble.

\section{Tumbling Selves: Embodiment to Enfleshment}

As we considered our selves tumbling, we drew inspiration from feminist phenomenologist Madeleine Grumet (1988), who affirmed that, as women, we must recognize and understand the role our bodies play in knowledge-making. Through the embodied acts of listening, attuning, and responding with/in our flesh as women and as researchers we felt the friction of Tenure as another body in our collective. Tenure provoked our poems, tears, arguments, victories, aches, paintings, tenderness, stitches through fabric, movements, and identities. After all, "it is through the hands, the flushed face, the gasp, and the squint that we express our dreams and fears, that we understand what animates the lives around us" (Grumet, 1988, p. 165). As artists, this animated and embodied awareness became enfleshed in and through our collective and individual forms of making. In the following, we more fully attend to our process of enfleshing Tumblr. 
Gloria: Am I a scholar first, or is "Black" always my antecedent?

Tenure: How does it feel to be a problem?

Gloria: To the underlying question, I answer "Whose problem?"

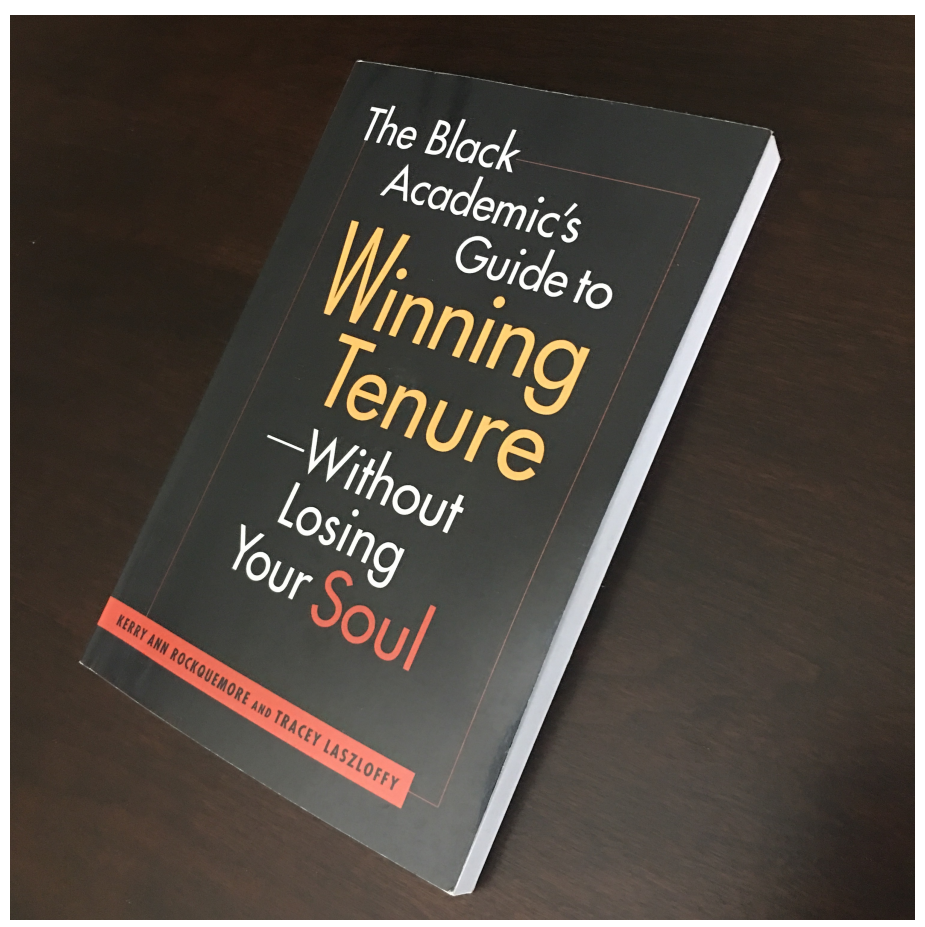

Figure 2. The Black Academic's Guide to Winning Tenure Without Losing Your Soul. (Rockmore \& Laszloffy, 2008)

\section{Tenure: Have you read it yet? I saw it in your mailbox...}

Gloria: While we may wish we lived in a post-racial world, race shapes every aspect of the tenure-track experience. I continually find myself in dialogue with other Black faculty about the stress of having to prove ourselves and not belonging. In addition to individual microaggressions, Black faculty describe not being given the benefit of the doubt, not being invited into networks and opportunities, being repeatedly mistaken for service employees or being completely ignored, and receiving a disproportionately high number of service requests because they are so few in number. Despite these challenges, Black faculty must teach effectively, publish research, and be "good" departmental citizens. The basic premise: that racism exists and we have to succeed anyway. 


\section{Enfleshing Tumblr through Art}

Our collaborative Tumblr blog revealed many types of embodied knowledge finding our way on new campuses, dialogues between ourselves and our students, works of art in various stages of completion, shifting from the dissertation to cohesive research agendas, to name just a few. Aligned with these awarenesses, the arts emerged as a viable means of challenging what representation means and how researchers might both live in/with, and make sense of, our inquiries. With the fundamental understanding of knowing as an embodied encounter and embracing the visual arts' ability to seek out qualitative nuances, provide empathy, give new perspectives, and tell about our capacity to engage with life (Barone \& Eisner, 2012), we desired to enflesh the Tumblr postings in, through, and with arts-based modes of representation that enabled us to more fully realize the creative potential of our narratives. These arts-based modes of enfleshing took various forms: relational artmaking, GIS mappings, visits to each other's campuses and homes, a working table installation, individual artmaking, and a visual journal. We culled these pieces together in the curation of a traveling exhibition of our work; we discuss the emergence of each enfleshed work below.

\section{Relational Artmaking with Others in Academia}

As we have indicated, the Tumblr platform created a space of relationality allowing us to write with, read, and respond to one another as we traversed the tenure track. One of Sara's posts encompassed a powerful question when she asked: Are there others that feel this? Her question inspired us to look beyond the immediacy and intimacy of our group of four women, wondering how opening up our questions and queries to a larger community might inform our work. Drawing inspiration from Finley's (2008) call for participatory ABR as well as contemporary artists working with mapping and relational aesthetics (for example, New York-based contemporary artist Nobutaka Aozaki, 2012), each of us installed interactive displays on our respective campuses, inviting those around us to consider the question: What informs your movements in academia? The responses we collected act as the beginning of this work-in-progress. Next, we activated this question at an academic conference, inviting session attendees to write, draw, and/or discuss their own responses during our presentation (Hofsess, Shields, Wilson, \& Guyotte, 2016). Additionally, attendees could engage with us outside of the conference space through handmade books imprinted with a $Q R$ reader. 
At our exhibitions, we extended our query by inviting viewers to engage with us in recording responses to this question on paper scraps, and pinning their responses to the wall (see Figure 3). Thus, this work opened relationally toward academic others as they considered their respective movements as well as the collectivity of movements contributed. Incited by our question: Are there others that feel this?, the participatory aspect of these encounters enfleshed Tumblr through a relational process of inviting and responding.

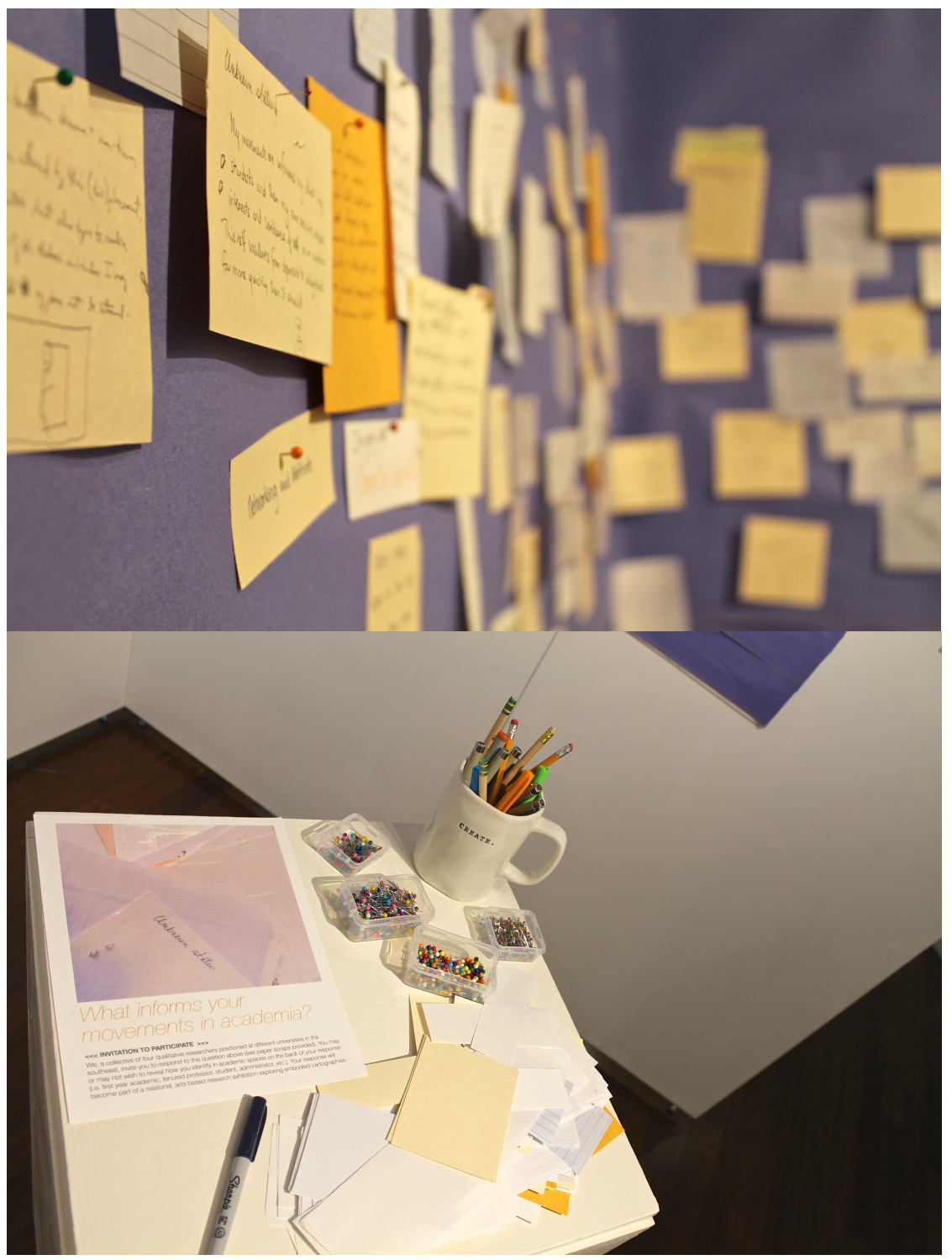

Figure 3. What informs your movements in academia? Views of the invitation and pinned responses on a gallery wall 


\section{GIS Mappings}

In further considering our relationality, we found it compelling to enflesh ourselves in the midst of overlapping trajectories, mapping the places before and after the graduate program that culled us together, albeit briefly. More than that, we desired to not only examine our paths to tenure, but also to question how we found ourselves in academia by way of careers as Kindergarten-12th grade art educators in public schools, in our prior graduate studies, through international travel, and so on. As we considered how our geographical movements converged and diverged in our paths toward academia, we thought about representations of time-space. Envisioning how we might visually explore these movements, we invited Michelle Wooten, a graduate student who carries an expertise in GIS (geographic information system), to collaborate with us.

GIS provides a space to create and manipulate visual information, to explore and analyze various pieces of data. Working closely with the Michelle, we created a series of projections that animated our various movements - sometimes individual, other times layering and converging, as we traversed our entangling personal, academic, and professional topographies. This piece, projected on a large blank gallery wall in our art exhibition, became an animated enfleshment, inquiring into the interconnected relationship between time, space, and movement, and as a means of nudging ourselves and the viewer to consider how bodies might be represented in GIS mapping (see Figure 4).

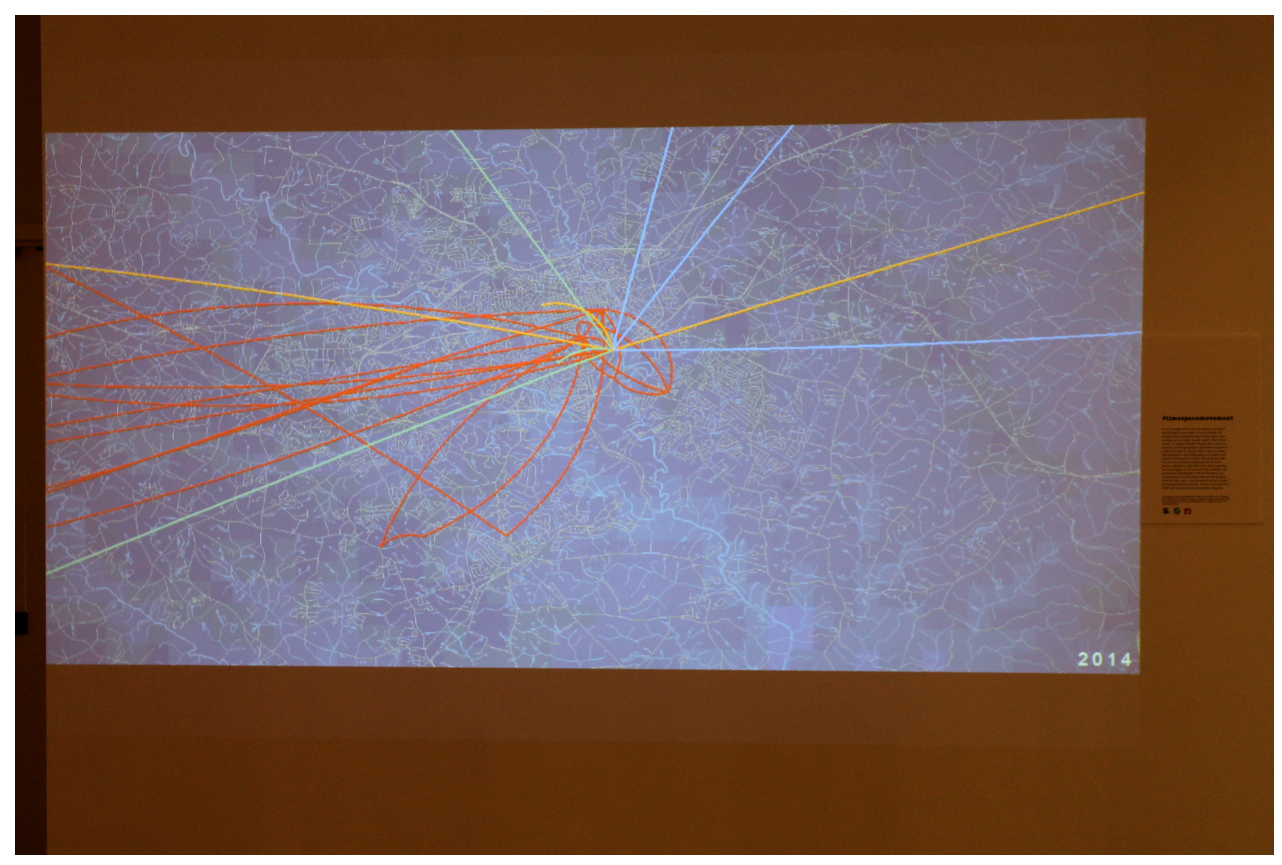

Figure 4. Movement convergence/divergence. View of GIS projection in the gallery 


\section{Visits}

Another part of our movements in this work encompassed our travels to visit each other. At the start of the project, we committed to visiting the campuses and homes of each collaborator. Avoiding the dense traffic of college football fanatics on a cold and rainy mid-fall weekend in Alabama; breaking bread at a mid-winter dinner gathering in Tennessee; moving in and through the sticky heat of Florida for glimpses of beaches, galleries, and classrooms; finding ourselves socked in by thick fog at a fall farmer's market nestled deep in the Appalachian Mountains, the trajectories of these visits embodied something remarkable. At the outset of each visit, we individually grumbled and moaned through our collective excuses: too busy, too hard to get away, too expensive, too much right now. Yet, the time and energy it took to be in the same space, not merely encountering one another through the virtual spaces of Tumblr, granted us the chance to build in ways we could not have done alone or in virtual meetings through Skype. We left our home visits renewed, inspired, and carrying a new optimism toward our tenure track journeys and our research. These visits became an important facet of our inquiry, the place where much of our writing and planning took place, as well as offering time to reminisce on our embodied academic experiences amidst late-night conversations, hugs, and eye contact. They became a time where flesh-met-flesh.

\section{\#Working Table}

When we came together in the flesh, we often, and for the duration of the visits, found ourselves assembling around our respective dinner tables. Though comfortable couches and armchairs were always readily available, the true "work" of our inquiry occurred while seated in hard wooden chairs with laptops, papers, and writing/drawing implements sprawling and entangling with crumbs, drinks, and eating utensils. Inspired by our inquiry process and the "working tables" of international contemporary artist Gabriel Orozco (2005), we conceptualized this work as a central part of our exhibition. What happened to our work around these tables? Time, tempo, and materiality all tended to slip away in the doing and writing up of qualitative inquiry. We turned to artsbased research to resist this manner of flattening and to render these parts of the process visible.

\#Working Table (Figure 5) is an installation from our exhibit that documents the material layers of our collaborative process. Artifacts and objects become the enfleshment of encounters sparked and stimulated at the various tables in each other's homes. In curating these items, we marked each with a hashtag that demarcated the agency and salience of the object and neatly displayed each item on a table-like surface in the gallery spaces. For us, the table-as-installation is reminiscent of an archaeological 
dig site with found objects labeled and organized. We asked ourselves: What would it look like if someone were to excavate our work around these tables? What would they find? How do these materials become part of our enfleshment in this work? To be sure, the objects appearing on the \#WorkingTable were meaningful and vital forces in our cartographies that furthered the enfleshment of Tumblr, extending from our visits, mapping our working process, and expanding our relational experiences as they encompassed material, nonhuman objects.

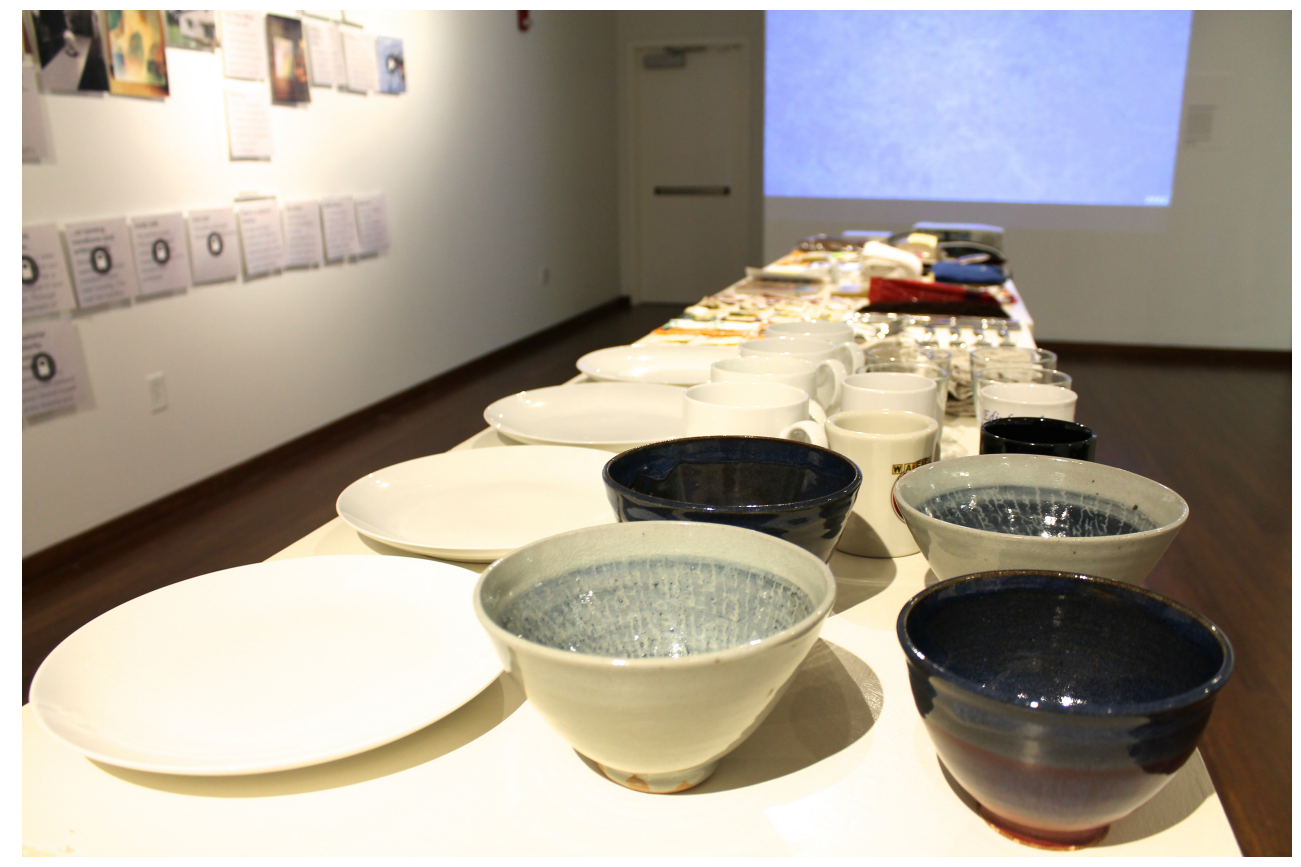

Figure 5. \#WorkingTable as it appeared in the gallery

\section{Individual Artmaking}

It became important to us to move through and enflesh moments pertaining to our academic journeying as individual artists, in addition to our collaborative artmaking. As we began to conceptualize the gallery show, we asked ourselves: What more could be said, felt, understood about this academic journey, this phase of life, through our individual artistic practices? This was the guiding question as we retreated into our offices, homes, and studios to make, alone. While we did not want to force creativity or induce stress by imposing too much structure around this experimentation, we each committed to creating at least one piece for our collaborative exhibition. Our backgrounds in fiber arts, papermaking, drawing, painting, and book arts guided the various forms of representation we each took. In what follows, we share a bit about the intention and expression of four individual works included in our exhibition. 


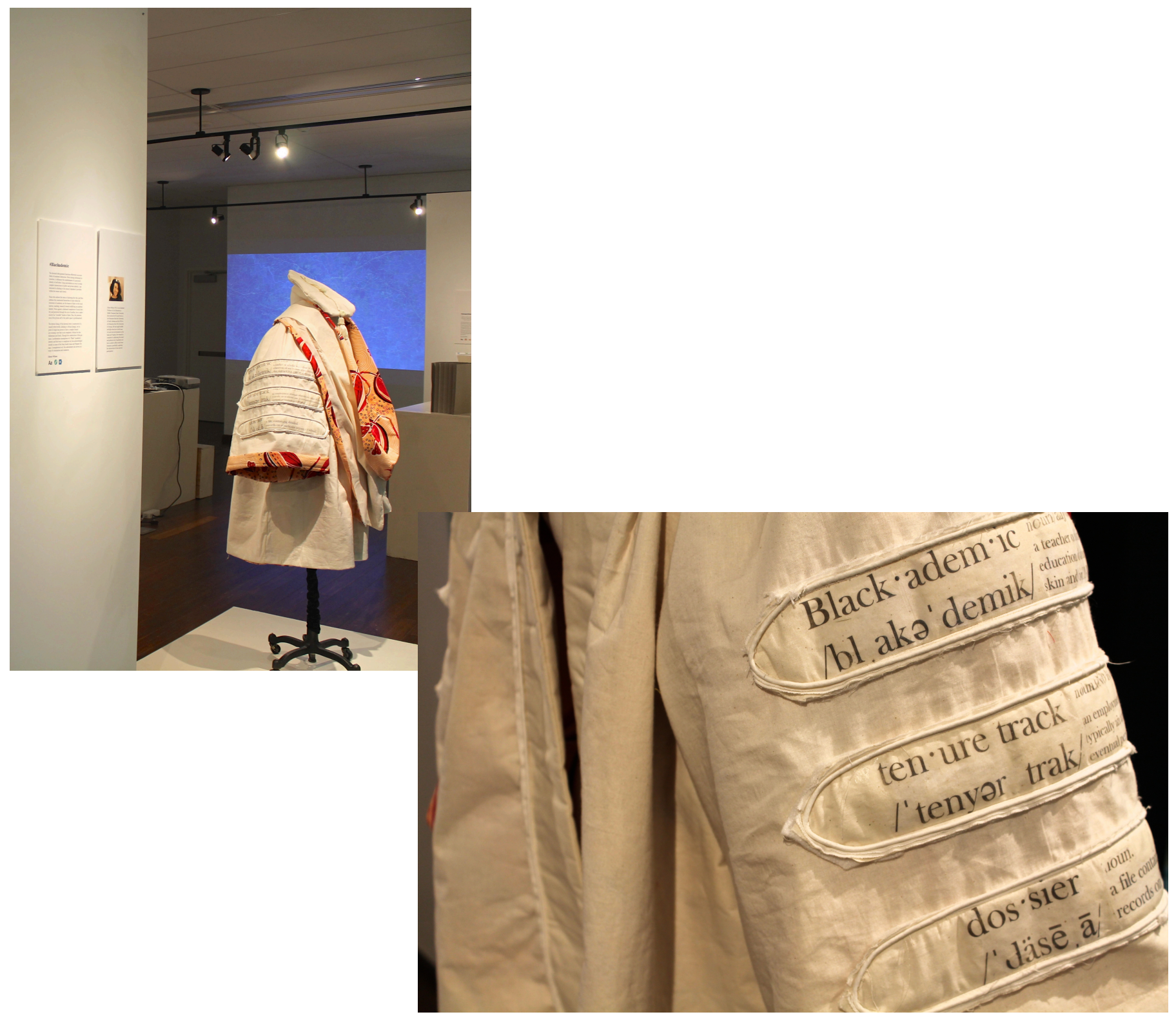

Figure 6. \#Blackademic (left) and detail of left sleeve (right).

In designing and creating a doctoral robe, \#Blackademic, Gloria examines how this garment functions effectively as an aesthetic of academic distinction. Worn during ceremonial interaction, it influences the establishment of a perceived identity of self/ other. Through the construction of this garment, Gloria problematizes the experiences of a "Black" academic (identity) within the structures of the academy. 


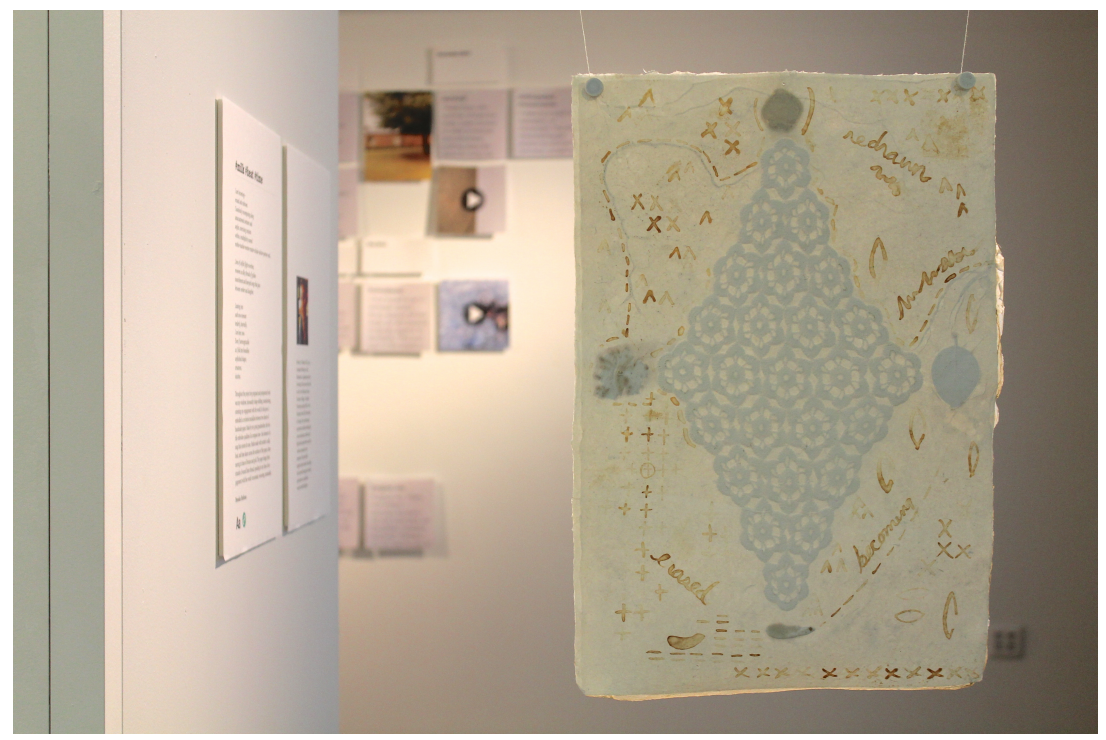

Figure 7. \#milk \#heat \#time, cotton and abaca with crochet, petal, leaf, and seed

In \#milk \#heat \#time, Brooke represents her pregnant and postpartum body as a compass rose-the element of a map that attunes and orients its user. The work in Figure 7 includes an embedded, crocheted medallion (aimed to evoke the compass rose) between two sheets of handmade paper, made by her great grandmother.

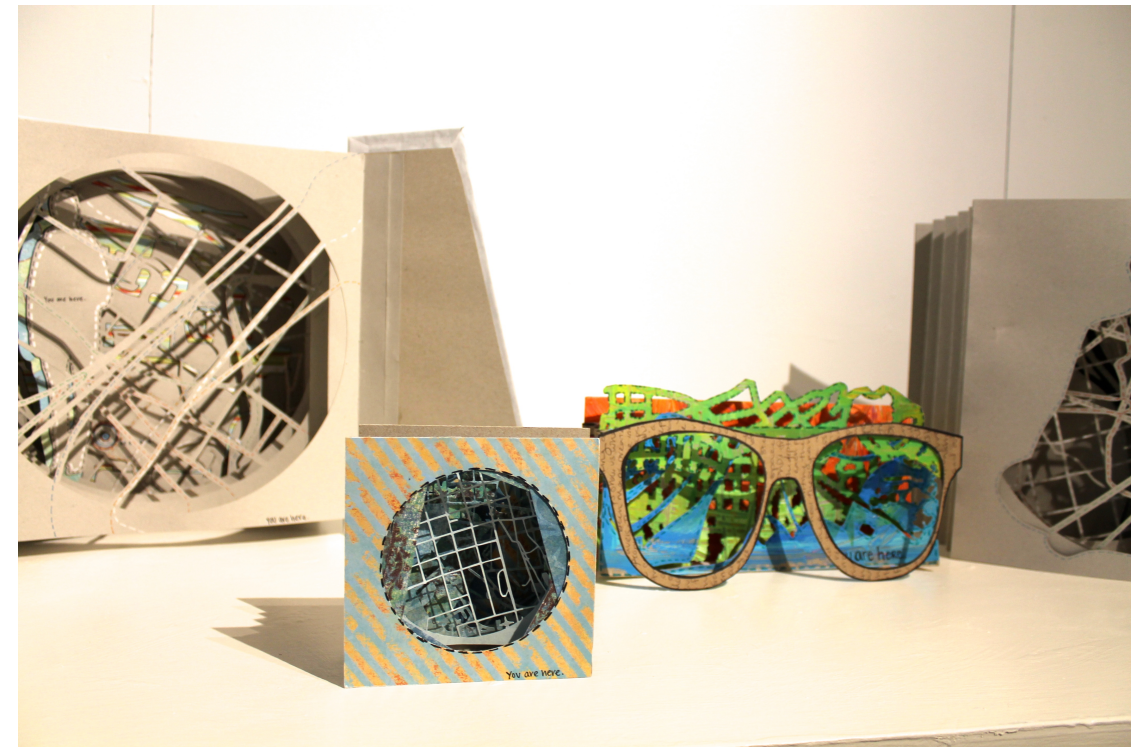

Figure 8. Detail of \#fiveyearsandcounting. 
Creating a series of tunnel books, \#fiveyearsandcounting, Sara wanted to explore the transitions she experienced from the start of her $\mathrm{PhD}$ and into her first years as an assistant professor. The decision to have five tunnel books is representative of the four-year journey, taken to get to this point in her academic career, and the fifth disassembled book represents the year she was progressing through at the time (Figure 8). Looking closely, you can see the figure move throughout the map layers as the time progresses.

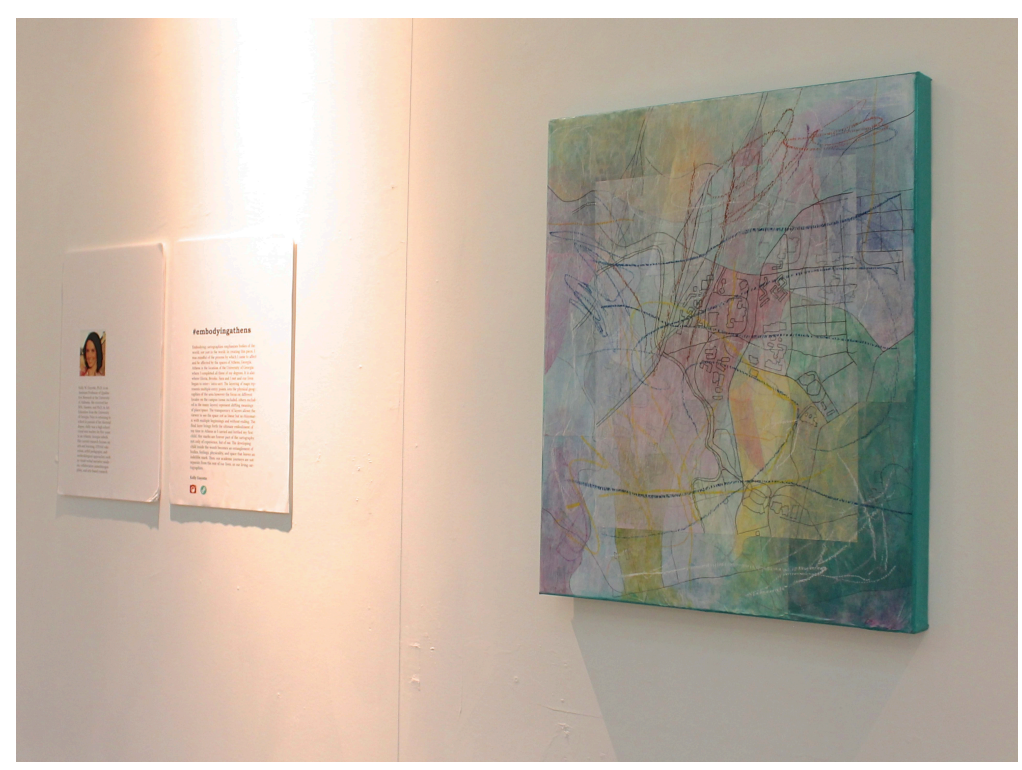

Figure 9. Detail of \#embodyingcity.

Kelly created \#embodyingcity as a mixed media artwork inspired by her time in Athens, Georgia where she attained all three of her degrees and spent a significant portion of her life. The transparency of mapped layers invites the viewer to see time/ space as rhizomatic with multiple beginnings, without endings. Marks made by her daughter leave an indelible mark on her movements in and between academic life (Figure 9).

These individual artworks were made public in gallery exhibitions of our artsbased project and served as extensions of the very ideas that permeated through our Tumblr postings - intersections between, race, gender, motherhood, and place in our tenure track journeys. Thus, artmaking nurtured a space where we could clothe our embodied experiences through artful materiality and create spaces for our individual pieces to dialogue differently with one another. 


\section{Visual Journal}

Similar to individual artmaking, another intimate part of our respective artistic processes were journals. We are visual journal keepers, and pages from our private journals and research notebooks appeared from time-to-time on the blog. Knowing this about ourselves caused us to wonder together how the virtual reflections posted to the Tumblr site might contrast those made in a pen and paper research notebook. As such, early in the project we collectively designed a handmade journal using scrap papers found in our offices and homes; Brooke stitched the papers together with a Japanese stab binding. This shared journal has been circulating among our group for the past year, providing us the opportunity to engage reflectively as individuals, as well as responding, revising, or expanding on each other's musings.

This journal was shared with viewers at our exhibits and demonstrates another layer of our inquiry. Just as we appreciated the immediacy and convenience of being able to read postings and respond via Tumblr, we yearned for the viscerality of artmaking - we are also makers. The journal, then, offered us a Slow-ness (Ulmer, 2017), a relational process that disrupted the rhythms of oft desired immediacy and convenience (or production) in order to consider and create through an enfleshed aesthetic process of sensing/feeling/connecting. Similar to our individual artwork, it was through visual journaling that we worked differently, and began to appreciate both the affordances and even the constraints that each layer of our process provided. Taking the time for such appreciation provided a more nuanced understanding of our embodied inquiry, the various ways that we worked with and enfleshed Tumblr, and the layers therein.

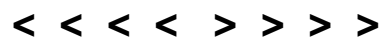

Kelly: I find myself in an in-between space. Body slipped off one edge though still pressed longingly against its familiarity. This past year in the academy has led to shuttering realizations of where I am and where I might be moving, yet I am fearful of the wandering feeling that infiltrates my being. Amidst an ontological and epistemological shift, I no longer feel the ground beneath my feet. Or, if it is there, it shifts in fluid swells that resist stasis. The incessant movement, therefore, keeps me from a grounding that I once had. It evokes frenzy, an embodied fluttering within my chest and a knotted tension in my gut. 


\section{Tenure: Where do you belong? With whom? What will you say? Who will want to listen?}

Kelly: The fear grips tightly from time to time yet I refuse to seek solid ground. There is value in being where I am, and I keep allowing myself to fall further into the interstices. Moving around/within/among different thinkers and philosophers.

Tenure: I heard you say recently, "I feel homeless."

Kelly: Perhaps this is not true. I am at home in my body. A body that pulses with the beating of the lifeworld I inhabit and that inhabits me. It is more likely that I am becoming attuned to this body. Perhaps I am becoming liberated, or just becoming, through this wandering and wondering, sloughing off the old skin and regenerating through the new.

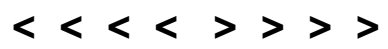

\section{Implications for Art/Research}

In this project, focused on art intervention as inspiring movement from embodiment to enfleshing; we activated the boundaries between artist, teacher, researcher, ethnographer, and collaborator. For us, there is something inherently productive about such boundary-blurring when it creates new opportunities for inquiry. In this section, we consider how this project contributes new understandings and representations of arts-based collective autoethnography as methodology. We mull over how visual arts modalities, collaborative research, and autoethnography contributed to what unfolded in this project. Then, we conclude by considering what attuning to our multimodal art interventions offers those who blur the line between visual artists and researchers.

\section{Visual Arts}

By opening autoethnographic inquiries to encompass the visual arts, art becomes more than living discourse: it constitutes a relational event that brings together maker and observer (Bourriaud, 2002). What happens, then, when embodied knowing materializes through living, interdisciplinary, relational, shifting, aesthetic, performative, and multimodal processes as entangled within our ongoing, ever-realizing tumbling selves? As Sullivan noted, "we live in an era of hybridity" and the visual arts in/as research open new routes through complicated contexts with permeable boundaries 
(2005, p. 192). Perhaps this is why what began as a project developed around only a shared Tumblr blog, fractured and spilled over into a myriad of ways of working, responding, reflecting, and enfleshing. Working through only one platform - despite the multimodal potentiality of Tumblr, simply couldn't capture the affective, material, embodied, and ephemeral qualities of our journeymaking, nor our embodied sensemaking. As artful-makers, we desired the viscerality of creating differently, of tools, of spatial and compositional considerations, of a longing that only artmaking satiates. To be sure, we recognize that others might not need such an outlet; however, for us, in this inquiry, moving toward the visual arts became a necessary aspect of our moving between embodiment and enfleshment.

\section{Collaborative Research}

In addition to the visual, we explored what it meant to work individually, collaboratively, and as individuals in/among a collective. Chang and colleagues explained that collaborative autoethnography cultivates a space for researchers to both "interrogate their self-world by themselves" and to "work together, building on each other's stories, gaining insight from group sharing, and providing various levels of support" (2013, p. 23). Through our inquiry, we appreciated the freedom of movement between individual and collective, and the support through both the research process as well as the tenure process. We found it productive to work with, against, and through our individual experiences, postings, and artworks as we moved in and out of these spaces alone and together. The challenges that arose presented us with opportunities to move in and through difficult spaces and conversations around issues of broader significance like sexism, racism, marriage, motherhood, theory, while also feeling the body of Tenure among us. To be sure, the collective aspect of the process was instrumental in creating these dialogic spaces just as the auto- reminded us that our individual experiences were heard and valued by the group.

\section{Autoethnography}

Autoethnographies, as we have discussed, explore the self (auto) in relation to culture (ethno). In our work, we were interested in how we tumbled from doctoral programs to the tenure track, and how we came to know/experience the culture of academia through this poignant and embodied shift. While our individual experiences often differed, we also found resonance through shared facets of the tenure process. For instance, the very real presence of Tenure as a body in our collective was something we could not ignore. Thus, even as we focused on self-in/of-culture, we became aware of the many other bodies that pervaded our autoethnographies and, subsequently, how bodies, our art, and our collective narratives all pervaded each other. 
With this in mind, the artful could not be disentangled from the collective, nor from the autoethnographic. Like our artmaking, each layer of our methodology became enfleshed through a rich process of exploration, discovery, questioning, and further movement.

\section{Coda: Tumbling toward Enfleshment}

Through an inquiry into our tumbling academic selves, we came together to consider how our bodies and the bodies we encounter(ed), enmesh, entangle, respond, create; and how these entanglements could be explored through conceptual and aesthetical enfleshment. Our backgrounds as artists and researchers nudged us toward the multilayered and multimodal affordances of Tumblr as a means of staying connected and creating a space to document our experiences on the tenure track. That was, in fact, only the beginning. As time passed, Tumblr became more than a virtual environment, it was a space for artful intervention in the structures of academia as we made sense of what it meant to be women on the tenure track. Further, it cultivated an awareness (one felt in the prickles, sweat, warmth of our flesh) of another body that shadowed us in our inquiry: that of Tenure. Through these facets of our work, we became interested in the movement from embodiment to enfleshment, the place of Tenure among us, and the role of art intervention in the collective autoethnographic process.

In this article, we have focused on providing you, our reader, with insight into our methodological process. We turned to art to intervene in dominant narratives of tenure, locating Tenure as a body, one that affects and dialogues with each of us, and all of us, as we tumble as women on the tenure track. With a desire to make our voices heard, we used artmaking to speak both with and against academic expectations, to make visible our successes and struggles, and to sometimes question the very path we chose. For us, these interventions became an essential part of our collective autoethnography - new things becoming possible through art, and possibilities for both reflexivity and relationality cultivated in the oft-isolated academic existence. We hope that we have demonstrated how art can create unique spaces for four women to inquire into their tenure experiences. Although we do not suggest that our experiences might somehow be replicable or that others should "do as we did" in this inquiry, we do hope that our journey from embodiment to enfleshment offers new directions for bringing art and research together. We offer our experiences on the tenure track as an invitation for others to tumble with us - becoming attuned to how our flesh responds, and becoming aware of the other bodies we meet along the way. 


\section{Acknowledgements}

We wish to thank Michelle Wooten for her collaboration and assistance on various aspects of this project, particularly the ArcGIS projections she created for the gallery shows. We also thank Maureen Flint for her thoughtful assistance. 


\section{REFERENCES}

Aozaki, Nobutaka. (2012). From here to there (Manhattan) [Installation]. Retrieved from http://www.nobutakaaozaki.com/maps.html

Araujo, T., Neijens, P., \& Vliegenthart, R. (2015). What motivates consumers to re-Tweet brand content? Journal of Advertising Research, 55(3), 284-295. doi: 10.2501/JAR-2015-009

Armenti, C. (2004a). May babies and posttenure babies: Maternal decisions of women professors. Review of Higher Education, 27(2), 211-231. doi:

10.1353/rhe.2003.0046

Armenti, C. (2004b). Women faculty seeking tenure and parenthood: Lessons from previous generations. Cambridge Journal of Education, 34(1), 65-83. doi: 10.1080/0305764042000183133

Art Intervention. Retrieved from: http://www.tate.org.uk/art/art-terms/a/art-intervention

Barone, T. \& Eisner, E. (2012). Arts based research. Thousand Oaks, CA: Sage.

Bhattacharya, K. (2016). The vulnerable academic. Qualitative Inquiry, 22(5), 309-321. doi: $10.1177 / 1077800415615619$

Bledsoe, T. S., Harmeyer, D., \& Wu, S. F. (2014). Utilizing Twitter and \#hashtags toward enhancing student learning in an online course environment. International Journal of Distance Education Technologies, 12(3), 75-83. doi: 10.4018/978-1-5225-2584-4.ch060

Bleijenbergh, I. L., van Engen, M. L., \& Vinkenburg, C. J. (2013). Othering women:

Fluid images of the ideal academic. Equality, Diversity \& Inclusion, 32(1), 22-35. doi: 10.1108/02610151311305597

Bourriaud, N. (2002). Relational aesthetics [Esthetique relationnelle] (trans. S. Pleasance, F. Woods and M. Copeland). Paris, France: Les Presses du Réel.

Chang, H., Ngunjiri, F. W., \& Hernandez, K. C. (2013). Collaborative autoethnography. Walnut Creek, CA: Left Coast Press. 
Cord, B., \& Clements, M. (2010). Reward through collective reflection: An autoethnography. E-Journal of Business Education and Scholarship Teaching, 4(1), 11-18. Stable URL: http://www.ejbest.org/upload/ eJBEST_CordClements_2010_4(1).pdf

Drakitch, J., \& Stewart, P. (2007). Forty years later: How are university women doing? Academic Matters: The Journal of Higher Education, February, 6-9. Retrieved from https://academicmatters.ca/assets/AM-Feb-2007-Issue.pdf

Drüeke, R., \& Zobl, E. (2016). Online feminist protest against sexism: The German-language hashtag \#aufschrei. Feminist Media Studies, 16(1), 35-54. doi: 10.1080/14680777.2015.1093071

Eisner, E. (2002). The arts and the creation of mind. New Haven, CT: Yale University Press.

Ellis, C. S., Adams, T. E., \& Bochner, A. P. (2011). Autoethnography: An overview. Forum Qualitative Sozialforschung/Forum: Qualitative Social Research, 12(1), 273-290. Art. 10. Retrieved from http://nbn-resolving.de/urn:nbn:de:0114fqs1101108

Finley, S. (2008). Arts-based research. In Knowles, J. G. \& Cole, A. L. (Eds.), Handbook of the arts in qualitative research: Perspectives, methodologies, examples, and issues (pp. 72-82). Thousand Oaks, CA: SAGE. doi: 10.4135/9781452226545

Flaherty, C. (2016, August 22). More faculty diversity, not on tenure track. Inside Higher Ed [Web log]. Retrieved from https://tinyurl.com/yaza296k

Gasser, C. E., \& Shaffer, K. S. (2014). Career development of women in academia: Traversing the leaky pipeline. The Professional Counselor, 4(4), 332-352. doi: $10.15241 /$ ceg.4.4.332

Grumet, M. R. (1988). Bitter milk: Women and teaching. Amherst, MA: University of Massachusetts Press.

Guarino, C. M. \& Borden, V. M. H. (2017). Faculty service load and gender: Are women taking care of the academy? Research in Higher Education, 58(6), 672-694.

doi: 10.1007/s11162-017-9454-2 
Guyotte, K. W. (2018). The undecided narratives of becoming-mother, becomingPhD. In S. A. Shelton, J. E. Ewing, \& T. J. Grosland (Eds.), Feminism and intersectionality in academia: Women's narratives and experiences in higher education (pp. 37-48). Cham: Switzerland: Palgrave Macmillan.

Hindman, F. M., Bukowitz, A. E., Reed, B. N., \& Mattingly, T. J. (2017). No filter: A characterization of \#pharmacist posts on Instagram. Journal of the American Pharmacists Association, 57(3), 318-325. doi: 10.1016/j.japh.2017.01.009

Hirakata, P. E., \& Daniluk, J. C. (2009). Swimming upstream: The experience of academic mothers of young children. Canadian Journal of Counselling, 43(4), 283-294.

Hofsess, B. A. (2018, April). Mantra as medium: Cultivating necessary wisdom in aesthetic inquiry. Paper presented at the American Educational Research Association Annual Meeting, New York, NY.

Hofsess, B. A., Shields, S. S., Wilson, G. J., \& Guyotte, K. W., (2016, March). Choose your own adventure: Counter narratives with/in art education. Paper presented at the National Art Education Association National Convention, Chicago, IL.

Kidd, J. D., \& Finlayson, M. P. (2010). Mental illness in the nursing workplace: A collective autoethnography. Contemporary Nurse: A Journal for The Australian Nursing Profession, 36(1/2), 21-33. doi: 10.5172/conu.2010.36.1-2.021

Langer, S. (1951). Philosophy in a new key: A study in the symbolism of reason, rite, and art. New York, NY: Mentor Books.

Leavy, P. (2015). Method meets art: Arts-based research practice. New York, NY: Guilford.

Marschke, R., Laursen, S., Nielsen, J. M., \& Rankin, P. (2007). Demographic inertia revisited: An immodest proposal to achieve equitable gender representation among faculty in higher education. The Journal of Higher Education, 78(1), 1-26. doi: 10.1353/jhe.2007.0003

O'Donoghue, D. (2015). On the education of art-based researchers: What we might learn from Charles Garoian. Qualitative Inquiry, 21(6), 520-528. doi: 10.1177/1077800415581888 
O'Reilly, A. (2009). Maternal thinking: Philosophy, politics, practice. Toronto, ON: Demeter Press.

O'Reilly, A. (2008). Feminist mothering. Albany, NY: SUNY Press.

O'Reilly, A. (2006). Rocking the cradle: Thoughts on motherhood, feminism and the possibility of empowered mothering. Toronto, ON: Demeter Press.

Orozco, G. (2005). Working tables. New York, NY: MoMA.

Penney, S., Young, G., Badenhorst, C., Goodnough, K., Hesson, J., Joy, R., ... Vaandering, D. (2015). Faculty writing groups: A support for women balancing family and career on the academic tightrope. Canadian Journal of Higher Education, 45(4), 457-479.

Pithouse-Morgan, K., Naicker, I., \& Pillay, D. (2017). "Knowing what it is like":

Dialoguing with multiculturalism and equity through collective poetic autoethnographic inquiry. International Journal of Multicultural Education, 19(1), 125-143. doi: 10.18251/ijme.v19i1.1255

Poling, L. H., Guyas, A. S, \& Keys, K. (2012). Mothering curricula. Studies in Art Education, 54(1), 66-80. doi: 10.1080/00393541.2012.11518880

Rockquemore, K. A., \& Laszloffy, T. (2008). The Black academic's guide to winning tenureWithout losing your soul. Boulder, CO: Lynne Rienner Publishers.

Sanderson, J., Barnes, K., Williamson, C., \& Kian, E. T. (2016). "How could anyone have predicted that \#AskJameis would go horribly wrong?" Public relations, social media, and hashtag hijacking. Public Relations Review, 42(1), 31-37. doi: 10.1016/j.pubrev. 2015.11.005

Santiago, I. C., Karimi, N., \& Arvelo Alicea, Z. A. (2017). Neoliberalism and higher education: A collective autoethnography of brown women teaching assistants. Gender and Education, 29(1), 48-65. doi: 10.1080/09540253.2016.1197383

Savage, S. L. (2015). Mapping tenureland: A researcher stalled. Studies in Art Education, 57(1), 76-87. doi: 10.1080/00393541.2015.11666284 
Sullivan, G. (2005). Art practice as research: Inquiry in the visual arts. Thousand Oaks, CA: Sage Publications.

Ulmer, J. B. (2017). Writing slow ontology. Qualitative Inquiry, 23(3), 201-211. doi: $10.1177 / 1077800416643994$

Wilson, G. J., Shields, S. S., Guyotte, K. W., \& Hofsess, B. A. (2016). Desirable difficulties: Toward a critical postmodern arts-based practice. Journal of Social Theory in Art Education, 36, 114-125. 


\section{ENDNOTES}

1 In this paper, we capitalize "Tenure" to signal the presence of tenure as a body in our work. Lower-case instances of "tenure" refer to its common usage.

2 Tumblr is a free blog site launched in 2007 (https://www.tumblr.com/about) that affords users the ability to follow, post, and share through multiple expressive formats.

3 Hashtags are words or phrases that begin with a hash or pound sign (\#). They are used on social media to reference (and organize) certain topics. 